\title{
FLAVONOIDS FROM AERIAL PART OF ALGERIAN AJUGA IVA (L.) SCHREB.: THE HPLC-UV ANALYSIS AND ANTIOXIDANT CAPACITY
}

\author{
Fadhela Boukada*, BoumedieneMeddah \\ University of Mascara, Faculty of Science of Nature and Life \\ BP. 763 (UN 2901), Sidi Said, Mascara, Algeria \\ *Corresponding author; E-mail: fadelaboukada6@gmail.com
}

(Received January 9, 2021; Accepted May 5, 2021)

\begin{abstract}
The study deals with the evaluation of the antioxidant capacity of extracts from the aerial part of Algerian Ajuga iva. Extraction of flavonoids was carried out by $85 \%$ of methanol, then the crude extract was successively separated with ethyl acetate, butanol, and water. The in vitro antioxidant activity was assessed by 1,1-diphenyl-2picrylhydrazyl, reducing power, and thiobarbituric acid reacting substances assays. Extracts are subject to HPLC-UV analysis. The average total phenol contents of extracts vary between $3.87 \pm 0.17$ and $149.74 \pm 3.94$ (gallic acid equivalent per gram of dry extract). Furthermore, tested extracts exhibited a broad range of flavonoid contents varying from $1.54 \pm 0.09$ to $41.18 \pm 1.03$ (catechin equivalent per gram of dry extract). Butanol and ethyl acetate fractions displayed the highest antioxidant activity. A good correlation between the phenolic and flavonoid contents and the antioxidant activity was observed. Rutin, caffeic acid, quercetin, p-coumaric acid, luteolin, and cinnamic acid were present in the extracts. The plant could be a potential source of antioxidant agents.
\end{abstract}

Keywords: Antioxidant effect, flavonoids, polyphenols, HPLC.

\section{INTRODUCTION}

The history of medicinal plants is associated with the evolution of civilizations. In all regions of the world, the history of peoples shows that these plants have always occupied an important place in medicine since antiquity. It was only in the 20th century that scientists became interested in this subject (JANSSEN et al., 1976).

The activities of these curative plants are evaluated by their chemical components. Plants synthesize secondary metabolites, which are molecules that are indirectly essential to the functioning of plants, as opposed to primary metabolites that are vital for vegetal life (FAVIER, 2003). Flavonoids are secondary metabolites and an unusually large group of naturally occurring phenolic compounds ubiquitously distributed in plants. The past two decades has witnessed a renewed interest in the study of flavonoids and of their biological interactions. Flavonoids are known for their pharmacological, biochemical properties, and antioxidant activities (CROZIER et al., 2006). 
Several studies have shown that flavonoids have great potential as antioxidants agents. In addition, a lot of research is currently being done on natural antioxidants that act as free radical scavengers. The excessive production of these radicals can be harmful to the body, they damage many cellular components as diverse as proteins, lipids, or DNA, causing oxidative stress (VAN ACKER et al., 1998).

A wide range of analytical techniques is used for the characterization of flavonoids extracted from medicinal plants, including high performance liquid chromatography (HPLC), either single or coupled with mass spectrometry. In recent years, HPLC has been the analytical method that has dominated the determination of flavonoids (RoBBINS, 2003).

Thanks to geographical location Algeria is home to rich and diverse vegetation. The genus Ajuga that belongs to the family Lamiaceae comprises at least 301 species (ZAFAR and BADIÀA, 2009). Flavonoids and tannins are found in large quantities in Ajuga iva. It also contains anthocyanins, phenolic acids, and other substances, in particular ajugarin (EL HILALY et al., 2004). Ajuga iva is an aromatic plant that grows from spring to late summer, in deep soils at $2700 \mathrm{~m}$ altitude. It is widespread in the Mediterranean region: southern Europe and northern Africa, especially in Algeria, Morocco, Tunisia, and Egypt (BATANOUNY et al., 1999). This small, bitter-tasting perennial, $5-10 \mathrm{~cm}$ long, with creeping, hairy green stems, has oblong to linear, pubescent leaves, 14 to $35 \mathrm{~mm}$ long. The flowers are purple, pink, or yellow, $20 \mathrm{~mm}$ long (HALIMI, 2004). This plant species has already been the subject of several studies, which show a broad spectrum of biological effects of extracts and essential oils including hypoglycemic (CHABANE et al., 2013), anti-inflammatory (BOUDERBALA et al., 2008), antimicrobial (ZERROUG et al., 2011), and antioxidant (TALEB-SENOUCI et al., 2009).

The aim of this work is to study the phenolic content of aqueous methanolic extracts and their solvent fractions of $A$. iva collected from Algeria. As well as the antioxidant potential was evaluated by employing DPPH radical-scavenging, reducing power, and lipid peroxidation assays to establish a possible correlation between polyphenol and flavonoid contents and antioxidant activity.

\section{MATERIAL AND METHODS}

\section{Plant material, extraction, and separation}

The plant was collected from Mascara, Algeria and was botanically identified by Dr. Righi Kada in the agricultural science department at the University of Mascara Mustapha Stambouli. The plant material was dried at room temperature and ground into powder using a shredder. The plant powder (100 g) was extracted by the classical method of maceration at room temperature with $85 \%$ of methanol according to the protocol described by MERGHEM et al. (1995) to obtain the crude extract. The hydromethanolic extract was evaporated and then dissolved in distilled water. The solution was successively partitioned with ethyl acetate, butanol, and water.

\section{Total phenolic content}

The total phenolic content was determined following the protocol applied by MiLIAUSKAS et al. (2004). In a test tube, $1 \mathrm{~mL}$ of known concentration extract was mixed with $5 \mathrm{~mL}$ of Folin-ciocalteu reagent (2M) diluted 10 times and $4 \mathrm{~mL}$ of a $75 \mathrm{~g} / \mathrm{L}$ sodium carbonate solution $\left(\mathrm{Na}_{2} \mathrm{CO}_{3}\right)$. The absorbance was measured at $765 \mathrm{~nm}$ after incubation for 1 hour at room temperature. The calibration curve is made by gallic acid. The amount of phenolic content was calculated as gallic acid equivalent per gram of dry extract (mg GAE/g $\mathrm{DE})$. 


\section{Total flavonoid content}

The total flavonoid content was determined according to the method adopted by ARDESTANI and YAZDANPARAST (2007). Each extract solution $(500 \mu \mathrm{L})$ was mixed with $2 \mathrm{~mL}$ of distilled water and $150 \mu \mathrm{L}$ of $\mathrm{NaNO}_{2}$ solution (15\%). After $6 \mathrm{~min}, 150 \mu \mathrm{L}$ of $\mathrm{AlCl}_{3}$ solution (10\%) was added, the mixture is left for $6 \mathrm{~min}$. After that, $2 \mathrm{~mL}$ of $\mathrm{NaOH}$ solution (4\%) was added. Immediately, the mixture was completed with distilled water until the volume reached $5 \mathrm{~mL}$. After $15 \mathrm{~min}$ of incubation, the absorbance was measured at $510 \mathrm{~nm}$ against a blank containing all the solutions except extract. The calibration curve is made by catechin. Results were expressed as catechin equivalent per gram of dry extract (mgCE/g DE).

\section{Antioxidant activity}

The antioxidant activity of the samples was investigated using three methods: DPPH radical assay, reducing power assay, and thiobarbituric acid reacting substances assay.

\section{DPPH radical assay}

A volume of $50 \mu \mathrm{L}$ of various concentrations of the extracts in methanol was added to $1950 \mu \mathrm{L}$ of a methanol solution DPPH $\left(6.10^{-5} \mathrm{M}\right)$, this mixture is strongly stirred for 30 seconds. Then, incubated for $30 \mathrm{~min}$ at room temperature in the dark. Absorbance was measured at $517 \mathrm{~nm}$ using methanol as blank (SHIMADA et al., 1992). Ascorbic acid and catechin were used as a positive control. The percentage inhibition (PI) of free radical formation was calculated according to the following formula:

$$
P I=\left(1-A_{1} / A_{0}\right) \times 100
$$

where $A_{1}$ is the absorbance of the extract and $A_{0}$ is the absorbance of the control. The results were estimated in terms of $\mathrm{IC}_{50}$ (the concentration of extract which inhibits $50 \%$ of free radicals present in the reaction medium). And it was calculated from the graph plotted of linear regression.

\section{Ferric reducing antioxidant power assay}

The reducing power of samples was determined as per the reported method of OYAIZU (1996). A quantity of $1 \mathrm{~mL}$ of each extract was mixed with $2.5 \mathrm{~mL}$ of sodium phosphate buffer $(0.2 \mathrm{M}, \mathrm{pH} 6.6)$ and $2.5 \mathrm{~mL}$ of potassium ferricyanide (1\%). After incubation for 20 min at $50^{\circ} \mathrm{C}, 2.5 \mathrm{~mL}$ of trichloroacetic $(10 \%)$ was added. After that, the mixture was centrifuged at $3000 \mathrm{rpm}$ for $10 \mathrm{mn}$. In a test tube, $2.5 \mathrm{~mL}$ of the upper layer fraction was mixed with $2.5 \mathrm{~mL}$ of distilled water and $0.5 \mathrm{~mL}$ of ferric chloride $(0.1 \%)$. The absorbance was measured at $700 \mathrm{~nm}$ and compared with standards. Increased absorbance of the reaction mixture indicated stronger reducing power. $\mathrm{EC}_{50}(\mu \mathrm{g} / \mathrm{mL})$ value is the effective concentration giving an absorbance of 0,5 for reducing power and it was obtained from linear regression analysis.

\section{Thiobarbituric acid reacting substances assay (TBAR)}

The anti-lipid peroxidation ability was assessed following the method described by TRIPATHI and SINGH (2001). In a test tube, $0.5 \mathrm{~mL}$ of rat liver homogenate $(\mathrm{KCl} 0.15 \mathrm{M})$ at a rate of $10 \%, 1 \mathrm{~mL}$ of potassium chloride $(0.15 \mathrm{M})$, and $0.5 \mathrm{~mL}$ of extract solution were mixed. Then, $100 \mu \mathrm{L}$ of ferric chloride $(1 \mathrm{mM})$ was added to initiate the lipid peroxidation. After incubation for $30 \mathrm{~min}$ at $37^{\circ} \mathrm{C}$, the reaction was stopped by adding $2 \mathrm{~mL}$ of ice-cold hydrogen chloride $(0.25 \mathrm{~N})$ containing trichloroacetic acid $(15 \%)$ and thiobarbituric acid 
$(0.38 \%)$, and $0.2 \mathrm{~mL}$ of butylated hydroxyl toluene $(0.05 \%)$. The reaction mixtures were heated at $80^{\circ} \mathrm{C}$ for $60 \mathrm{~min}$, cooled, and centrifuged at $6900 \mathrm{rpm}$ for $15 \mathrm{~min}$. the absorbance of the upper layer fraction was measured at $532 \mathrm{~nm}$ against a blank (contained all reagents without liver homogenate and drug). Synthetic antioxidants (ascorbic acid and catechin) were used as a positive control. The percentage of anti-lipid peroxidation (\% ALP) was determined by following formula:

$\% A L P=\left(A_{\mathrm{FeCl3}}-A_{\text {extract }}\right) \times 100 / A_{\mathrm{FeCl}}-A_{\text {normal }}$

$A_{\mathrm{FeCl}}$ : absorbance that indicates the level of lipid peroxidation (the reaction medium contained all the reagents without $\mathrm{FeCl}_{3}$ and without extract).

$A_{\text {extract: }}$ absorbance that indicates the level of anti-lipid peroxidation (the reaction medium contained all the reagents).

$A_{\text {normal }}$ : absorbance of the reaction medium which contained all reagents except extract and $\mathrm{FeCl}_{3}$.

$\mathrm{IC}_{50}$ is the value that corresponds to $50 \%$ of anti-lipid peroxidation, and it was obtained from linear regression analysis.

\section{HPLC analysis}

HPLC analysis of standards and extracts was performed using a Shimadzu Prominence-I HPLC apparatus equipped with LC-2030 pump and a photodiode array detector (PDA: LC-2030/2040). Flavonoids were separated on a C-18 reverse phase HPLC column (Supelco, $150 \mathrm{~mm} \times 4.6 \mathrm{~mm}$, particle size $5 \mu \mathrm{m}$ ) at $25^{\circ} \mathrm{C}$. Eluent A was the acetic acid aqueous solution (1\%) and eluent B was a methanol acetic acid solution. Separation was performed in an isocratic step at $2 \%$ of B for 2 min followed by a linear gradient from $2 \%$ to $20 \%$ of B in $10 \mathrm{~min}$, then to $100 \%$ of B in $65 \mathrm{~min}$ and $100 \%$ of B in 68 min with a flow rate at $0.8 \mathrm{~mL} / \mathrm{min}$. Flavonoids were identified by comparing their retention times and corresponding UV-Vis absorption spectra with standards.

\section{Correlation analysis}

Results were expressed as Mean \pm standard deviation (SD) of five separate experiments using Excel. Correlation coefficients between the total phenolic and flavonoid contents were determined from linear regression analysis using Excel.

\section{RESULTS AND DISCUSSION}

\section{Total phenol and flavonoid content}

The results of the levels of phenolic and flavonoid contents, as presented in Table 1, showed that the highest values of polyphenol were recorded in the ethyl acetate (149.74 \pm $3.94 \mathrm{mg} \mathrm{GAE} / \mathrm{g} \mathrm{DE})$ and butanolic fractions $(50.09 \pm 1.27 \mathrm{mg} \mathrm{GAE} / \mathrm{g} \mathrm{DE})$, while the aqueous fraction showed the lowest values $(3.87 \pm 0.17 \mathrm{mg} \mathrm{GAE} / \mathrm{g} \mathrm{DE})$. This order of fractions was confirmed by the results of ADJADJ (2009) who found that the ethyl acetate fraction is the richest in polyphenols and the aqueous fraction is the poorest. The contents obtained in our study are not in agreement with previous reports that proved that methanol and water are the most effective solvents for the extraction of polyphenols (MAKNI et al., 2013).

Flavonoids content of the investigated extracts varied from $1.54 \pm 0.09$ to $41.18 \pm 1.03$ mg CE/g DE (Table 1). The highest total flavonoid contents were found in the butanolic extract followed by the ethyl acetate fraction. Moreover, the lowest flavonoid contents were 
registered in the aqueous extract. These results indicate that flavonoids were better soluble in butanol and ethyl acetate. Our results are consistent with those conducted by ANOKWURU et al. (2011) where ethyl acetate was found to be the best solvent for the extraction of flavonoids. The variation of the phenolic and flavonoid contents might be due to the variation in procedure extraction, geographical conditions (EBRAHIMI et al., 2008).

Table 1. The total phenolic and flavonoid contents of extracts.

\begin{tabular}{llll}
\hline $\begin{array}{l}\text { Medicinal plant } \\
\text { Ajuga iva }\end{array}$ & Extract/Fractions & $\begin{array}{c}\text { Total phenolics } \\
\text { (mg GAE/g DE) }\end{array}$ & $\begin{array}{l}\text { Flavonoids } \\
\text { (mg CE/g DE) }\end{array}$ \\
\hline & Crude & $10.75 \pm 0.13$ & $5.43 \pm 0.45$ \\
& Ethyl acetate & $149.74 \pm 3.94$ & $34.61 \pm 3.01$ \\
& Butanolic & $50.09 \pm 1.27$ & $41.18 \pm 1.03$ \\
& Aqueous & $3.87 \pm 0.17$ & $1.54 \pm 0.09$ \\
\hline
\end{tabular}

Each value represents the mean $\pm \mathrm{SD}(\mathrm{n}=5)$

\section{Antioxidant activity \\ DPPH radical scavenging}

In this study, the DPPH method was chosen to evaluate the antioxidant activity of the extracts, because it is one of the fastest, simplest, and most effective methods due to the great stability of the DPPH radical (BOZIN et al., 2008).

As demonstrated in Table 2, all the extracts proved to have high antioxidant activities (between $39.53 \mu \mathrm{g} / \mathrm{mL}$ and $512.25 \mu \mathrm{g} / \mathrm{mL}$ ). The ranking of $\mathrm{IC}_{50}$ values is: ethyl acetate extract $>$ butanolic extract > crude extract > aqueous extract. Our results confirmed previous studies showing an important antioxidant activity of Ajuga iva extracts in other regions of its area (BAGHIANI et al., 2011). The essential oils extracted from Tunisian A. iva exhibited a potent DPPH radical scavenging effect (AYARI et al., 2013).

The mechanism of the reaction between antioxidant and DPPH radical depends on the structural conformation of the antioxidant (KOURI et al., 2007). According to the literature, polyphenols and flavonoids are very effective as agents reducing oxidative stress (Molyneux, 2004). From our results, it is clear that all the extracts can donate an electron to DPPH radical, so the DPPH radical scavenging effect could depend on the number of hydroxyl substituents (CAO et al., 1997).

\section{Ferric reducing antioxidant power assay}

In this assay, the presence of reducing agents causes the reduction of the $\mathrm{Fe}^{+3}$ ferrocyanide complex to the $\mathrm{Fe}^{+2}$ form. Indeed, the formation of $\mathrm{Fe}^{+2}$ can be monitored spectrophotometrically by measuring the absorbance of the blue color of the ferrous complex at $700 \mathrm{~nm}$ (KARAZOGLER et al., 2008). An increase in absorbance at this wavelength means stronger reducing power of the extracts (OZTURK et al., 2007).

Table 2 shows the reductive capability of extracts compared to ascorbic acid and catechin as standards. The ethyl acetate extract showed stronger reducing power $\left(\mathrm{EC}_{50}=\right.$ $780.16 \pm 1.56 \mu \mathrm{g} / \mathrm{mL}$ ) than other extracts. However, the reduction power of ascorbic acid $\left(\mathrm{EC}_{50}=49.09 \pm 0.23 \mu \mathrm{g} / \mathrm{mL}\right)$ and catechin $\left(\mathrm{EC}_{50}=46.82 \pm 1.01 \mu \mathrm{g} / \mathrm{mL}\right)$ was more pronounced than that of different extracts of Ajuga iva. This activity confirms the results of the DPPH radical-scavenging activity. BAGHIANI et al. (2011) found that extracts of Ajuga iva give a reduction power better than standards. 
A study conducted on the ability of iron reduction by phenols indicated that the catechol nucleus is the only structure that is positively associated with reducing power. According to this study, this structure increases the reducing power of a compound to $36 \%$ compared to another which does not contain one. They suggested that this activity was due to the participation of the groups -OH linked to the catechol nucleus (DEGRAFT-JOHNSON et al., 2007).

Table 2. Antioxidant activities for extracts and standards

\begin{tabular}{llccc}
\hline $\begin{array}{l}\text { Medicinal } \\
\text { plant }\end{array}$ & $\begin{array}{c}\text { Extract } / \\
\text { Fractions }\end{array}$ & $\begin{array}{c}\text { IC50 } / \mathbf{D P P H} \\
(\boldsymbol{\mu g} / \mathbf{m L})\end{array}$ & $\begin{array}{c}\text { EC50/Reducing } \\
\text { power }(\boldsymbol{\mu g} / \mathbf{m L})\end{array}$ & $\begin{array}{c}\text { IC50/ALP } \\
(\boldsymbol{\mu g} / \mathbf{m L})\end{array}$ \\
\hline Ajuga iva & Crude & $55.04 \pm 2.23$ & $2352 \pm 1.43$ & $1569.85 \pm 2.38$ \\
& Ethyl acetate & $39.53 \pm 1.39$ & $780.16 \pm 1.56$ & $419.63 \pm 1.71$ \\
& Butanolic & $44.17 \pm 0.43$ & $1173.52 \pm 2.89$ & $507.88 \pm 0.47$ \\
& Aqueous & $512.25 \pm 1.56$ & $4531.83 \pm 1.09$ & $2231.83 \pm 2.53$ \\
\hline Standards & Ascorbic acid & $17.21 \pm 0.67$ & $49.09 \pm 0.23$ & $208.85 \pm 1.55$ \\
& Catechin & $14.26 \pm 0.49$ & $46.82 \pm 1.01$ & $49.25 \pm 1.02$ \\
\hline
\end{tabular}

\section{Thiobarbituric acid reacting substances assay}

In this assay, malondialdehyde (MDA) is one of the final products of fatty acid peroxidation. MDA was measured spectrophotometrically at $532 \mathrm{~nm}$ by a thiobarbituric acid reactive substance (TBARS) method (FARAHMAND et al., 2013).

The butanolic and ethyl acetate phases exhibit a good lipid anti-peroxidation capacity. The strongest activity was exhibited by the ethyl acetate fraction $\left(\mathrm{IC}_{50}=419.63 \pm 1.71 \mu \mathrm{g} / \mathrm{mL}\right.$ ) and the weakest anti-lipid peroxidation activity was exhibited by the crude and aqueous extract (1569.85 $\pm 2.38 \mu \mathrm{g} / \mathrm{mL}, 2231.83 \pm 2.53 \mu \mathrm{g} / \mathrm{mL}$ respectively). Values obtained in our study are lower than the data reported by TALEB-SENOUCI et al. (2009), when studied the Tunisian Ajuga iva aqueous extract.

According to RATTY and DAS (1988), the flavonoid aglycones were more potent in their anti-lipid peroxidation ability than their corresponding glycosides. The structure-activity analysis demonstrated that the flavonoid molecule with polyhydroxylated substitutions on ring $\mathrm{A}$ and $\mathrm{B}, \mathrm{A}$ 2,3-double bond, a free 3-hydroxyl substitution, and a 4-keto moiety, would confer upon the compound potent anti-lipid peroxidation effect.

\section{Correlation analysis}

Several researchers have studied the correlation between polyphenol content and antioxidant properties. Some of them found a correlation between the phenolic content and the antioxidant activity, while others did not find a relationship.

There is a good correlation between the total phenol and flavonoid contents and the DPPH assay $\left(\mathrm{R}^{2}=0.68, \mathrm{R}^{2}=0.87\right.$, respectively). VeLIOGLU et al. (1998) had also reported good correlations for fruits and vegetables grain products between the total phenolic amount and the antioxidant capacity. On the other hand, our results are not in agreement with the data reported by WOJDYLO et al. (2007).

Regarding ferric reducing antioxidant power assay, there is good correlation between this method and the total phenols and flavonoids contents $\left(\mathrm{R}^{2}=0.80\right.$ and $\mathrm{R}^{2}=0.85$ respectively). This finding agrees with the study of WONG et al. (2006), which reported a good relationship between total phenolic content and antioxidant activity when studied the antioxidant activities of aqueous extracts of some medicinal plants using ferric reducing power assay. 
Correlation analysis reveals an excellent correlation between the total polyphenols and the anti-lipid peroxidation capacity of extracts with $\mathrm{R}^{2}=0.99$ and a moderate correlation between this assay and the levels of flavonoids with $\mathrm{R}^{2}=0.53$. The same results were found by VAMANU and NITA (2013) when studying the correlation of inhibition of lipid peroxidation with phenolic and flavonoids contents of extracts from wild edible Boletus edulis.

Since the chemical composition of extracts and structures of active compounds identified in extract are important factors governing the efficacy of natural antioxidants, the antioxidant ability of an extract could not be explained based on their phenolic and flavonoid contents (HEINONEN et al., 1998). For instance, it has been demonstrated that phenol compounds with para-dihydroxylation or a hydroxyl and a methoxy group are more effective than simple phenolics (SHAHIDI and WANASUNDARA, 1992).

\section{HPLC analysis}

As depicted in Figure 1 and Table 3, the HPLC chromatogram of butanolic extract of Ajuga iva showed the presence of caffeic acid, luteolin, and quercetin whereas the aqueous extract contained rutin, $p$-coumaric acid and quercetin. On the other side, ethyl acetate extract revealed the presence of caffeic acid, rutin, $p$-coumaric acid, luteolin, and quercetin, however, gallic acid, cinnamic acid and caffeic acid were found in the hydromethanolic extract.

Many reports have been published on the chemical composition of Ajuga iva, mentioning the evidence of numerous bioactive compounds, among them terpenoid, sterols, essential oils, and flavonoids (EL HILALY et al., 2004; ISRAILI and LYOUSSI, 2009). However, there are few references in the literature on the phenolic profile of this species. BOUDJLEL et al. (2015) showed that two flavonoids appeared to predominate, apigenin. and naringenin, in the aqueous infusion of Ajuga iva. However, KHATTELIA et al. (2020) reported the presence of caffeic acid, p-coumaric acid, rutin, and luteolin in the extract of the aerial part of Ajuga iva. These results are in accordance with our findings.

Table 3. Retention time (Rt), UV-Vis wavelengths of maximum absorption $\left(\lambda_{\max }\right)$, and concentration of phenol compounds.

\begin{tabular}{lllllll}
\hline & & & \multicolumn{4}{c}{ Concentration $(\boldsymbol{\mu g} / \mathbf{g})$} \\
Rt & Compound & $\lambda_{\max }(\mathbf{n m})$ & Crude & Ethyl acetate & Butanolic & Aqueous \\
\hline 15.30 & Gallic acid & 272 & 148221 & nd & nd & nd \\
25.21 & Cinnamic acid & 277 & 389955 & nd & nd & nd \\
27.22 & Caffeic acid & 219239323 & 420098 & 1339041 & 85552 & nd \\
30.08 & Rutin & 259355 & nd & 1261426 & nd & 237027 \\
39.70 & p-coumaric acid & 224309 & nd & 6.284 & 1802917 & 252826 \\
41.52 & Luteolin & 260348 & nd & 8,637 & 2244406 & nd \\
49.01 & Quercetin & 256372 & nd & 8.118 & 154055 & 93728 \\
\hline
\end{tabular}

nd - not detected

Several studies have been demonstrating the role of flavonoids and phenolics as antioxidant agents. SALUCCI et al. (2002) reported that gallic acid possesses a very high antioxidant capacity. In this order, YANG et al. (2008) reported that rutin exhibited strong DPPH radical scavenging activity and had effective inhibition of lipid peroxidation. On the other hand, luteolin exhibits a potent quenching effect on Fenton-induced 8-OHdG formation (CAI et al., 1997). According to the study of CHANG et al. (2017), caffeic acid and $p$-coumaric acid inhibited LDL oxidation and quenched radicals. Quercetin has a great antioxidant activity as shown by ZHANG et al. (2011). 


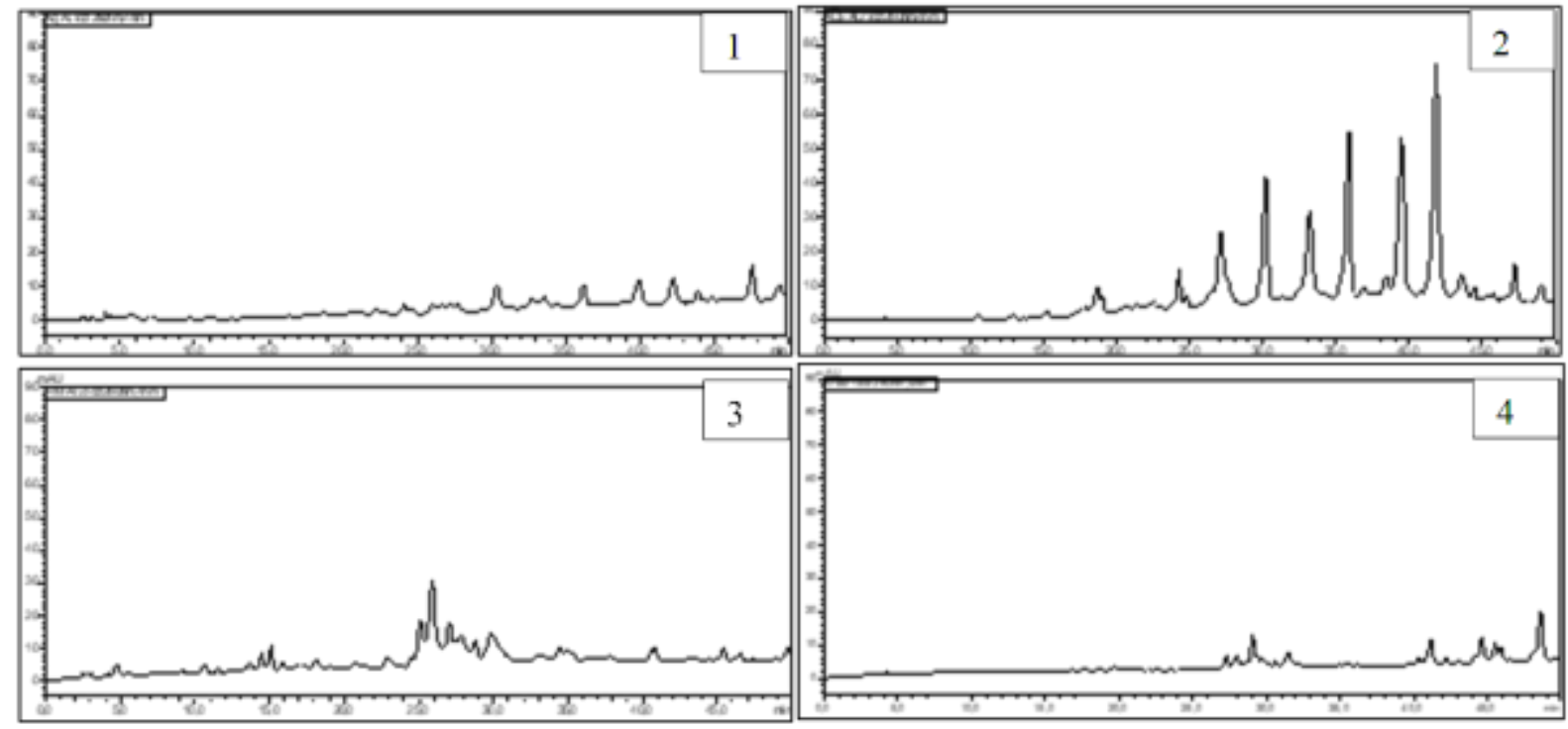

Figure 1. Representative high performance liquid chromatography profile of Ajuga iva extracts: Aqueous (1), Ethyl acetate (2), Hydromethanolic (3), Butanolic (4).

\section{CONCLUSIONS}

This study confirmed that Ajuga iva is a rich source of polyphenols and flavonoids and possesses antioxidant capacity mainly its ethyl acetate and butanol extracts. The antioxidant power of Ajuga iva extracts can be associated with their free radical scavenging properties. These data confirm their use in traditional medicine and encourage their application as alternative antioxidants. In addition, there is a need to isolate the compounds responsible for the activity, which may allow the development of a modern drug from this plant.

\section{References:}

[1] AdJADJ, M. (2009): Propriétés antioxydantes et activité inhibitrice de la xanthine oxydase des extraits de la plante medicinal Ajuga iva. Mémoire de magister en toxicologie cellulaire et moleculaire, Uniersité de Mentouri Constantine, Algérie. 86: pp. 51-52.

[2] Anokwuru, C.P., Anyasor, G.N., Ajibaye, O., Fakoya, O., Okebugwu, P. (2011): Effect of extraction solvents on phenolic, flavonoid and antioxidant activities of three Nigerian medicinal plants. Nature and Science 9 (7): 53-61.

[3] ARDESTANI, A., YAZDANPARAST, R. (2007): Inhibitory effects of ethyl acetate extract of Teucrium polium on in vitro protein glicoxidation. Food and Chemical Toxicology 45: 2402-2411. doi: 10.1016/j.fct.2007.06.020

[4] Ayari, B., Riah, L., Ziadi, S., Chograni, H., Mliki, A. (2013): Evaluation of antioxidant and antimicrobial activities of Tunisian Ajuga iva L. essential oils. Revue f. S. B. XI: 203-210.

[5] Baghiani, A., Boumerfeg, S., Adjadj, M., Ameni, D., Duermouni, M., KhelifiTouhami, F., ChAREF, N., Khennouf, S., ARrar, L. (2011): Antioxidants, free radicals 
scavenging and xanthine oxidase inhibitory potentials of Ajuga iva L. extracts. Free Radicals and Antioxidants 1 (4): 21-30. doi: 10.5530/ax.2011.4.5.

[6] Batanouny K.H., Abou Tabl S., Shabana M. and Soliman F. (1999): Wild medicinal plants in Egypt. Academy of Scientific Research and Technology. International Union for Conservation (IUCN). Egypt. ISBN: 977-5089-24-7

[7] Bouderbala, S., Lamri-Senhadj, M., Prost, J., LaCaille-Dubois, M.A., BOUCHENAK, M. (2008): Changes in antioxidant defense status in hypercholesterolemic rats treated with Ajuga iva. Phytomedicine 15: 453-461.

doi: 10.1016/j.phymed.2007.10.001

[8] Boudjlel, A., Siracusa, L., Henchiri, C., Sarri, M., Abderrahim, B., BaAli, F., Ruberto, G. (2015): Antidiabetic Effects of Aqueous Infusions of Artemisia herbaalba and Ajuga iva in Alloxan-Induced Diabetic Rats. Planta Medica 81 (9): 696-704. doi: $10.1055 / \mathrm{s}-0035-1546006$

[9] Bozin, B., Mimica-Dukic, N., SAmaJilik, I., Jovin, E. (2007): Antimicrobial and antioxidant properties of Rosmary and sage essential oils. Journal of Agricultural and Food Chemistry 55: 7878-7885. doi: 10.1021/jf0715323

[10] CAI, Q., RAHN, R.O., ZHANG, R. (1997): Dietary flavonoids, quercetin, luteolin and genistein, reduce oxidative DNA damage and lipid peroxidation and quench free radicals. Cancer Letters 119 (1): 99-107.

[11] CaO, G., Sofic, E., Priorb, R.L. (1997): Antioxidant and prooxidant behavior of flavonoids: structure-activity relationships. Free Radical Biology and Medicine 22: 749760.

[12] Chabane, D., Saidi, F., Rouibi, A., Azine, K. (2013): Activité hypoglycémique de l'extrait aqueux d'Ajuga iva L. schreber chez les rats diabétiques induite par l'alloxane. Afrique Science 9 (1): 120-127.

[13] Chang, M.Y., LiU, C.M., ShIEH, D.E., Chen, C.Y. (2017): Evaluation and analysis of phytochemical antioxidant capacity. Biomedical Research 28 (14): 6431-6434.

[14] Crozier, A., Clifford, M.N., Ashihara, H. (2006): Plant Secondary Metabolites Occurrence, Structure and Role in the Human Diet. Blackwell Publishing Ltd pp 372. doi: $10.1002 / 9780470988558$

[15] Degraft-Johnson, J., Kolodziejczyk, K., Krol, M., NowaK, P., Krol, B., NowaK, D. (2007): Ferric-reducing ability of selected plant polyphenols and their metabolites: implications for clinical studies on the antioxidant effects of fruits and vegetable consumption. Basic \& Clinical Pharmacology \& Toxicology 100 (5): 345-352.

[16] Ebrahimi, N.S., Hadian, J., Mirjalili, M.H., Sonboli, A., Yousefzadi, M. (2008): Essential oil composition and antimicrobial activity of Thymus caramanicus at different phonological stages. Food Chemistry 110: 927-931.

doi: 10.1016/j.foodchem.2008.02.083.

[17] El Hilaly, J., Lyoussi, B., Wibo, M., Morel, N. (2004): Vasorelaxant effect of the aqueous extract of Ajuga iva in rat aorta. Journal of Ethnopharmacology 93: 69-74. doi: 10.1016/j.jep.2004.03.020.

[18] Farahmand, S.K., Samini, F., Samini, M., Samarghandian, S. (2013): Safranal ameliorates antioxidant enzymes and suppresses lipid peroxidation and nitric oxide 
formation in aged male rat liver. Biogerontology 14: 63-71. doi: 10.1007/s10522-0129409-0.

[19] FAVIER, A. (2003): Le stress oxydant. Intérêt conceptuel et expérimental dans la compréhension des mécanismes des maladies et potentiel thérapeutique. L'actualité chimique: $108-115$.

[20] HaLIMI A.K. (2004): Les plantes médicinales en Algérie. 1ère Ed. BERTI, Alger pp: 156-157.

[21] Heinonen, M., Lehtonen, P.J., Hopla, A. (1998): Antioxidant activity of berry and fruit wines and liquor. Journal of Agricultural and Food Chemistry 48: 25-31.

[22] IsRAiLI, Z.H., Lyoussi, B. (2009): ethnopharmacology of the plants of genus Ajuga. Pakistan Journal of Pharmaceutical Sciences 22 (4): 425-462.

[23] Janssen, A.M., Scheffer, J.J.C., Svendsen, A.B. (1976): Antimicrobial activity of essential oils: A 1976-1986 Literature Review. Aspects of the test methods. Planta medica 53: 395-398. doi: 10.1055/s-2006-962755.

[24] Karazogler, A.A., Erdag, B., EMEK, Y.G., UYGum, D.A. (2008): Antioxidant activity and proline content of leaf extracts from Dorystoechas hastate. Food Chemistry 111: 400-407. doi: 10.1016/j.foodchem.2008.03.089

[25] Khattelia, A., Benabderrahima, M.A., Trikia, T., Guasmi, F. (2020): Aroma volatiles, phenolic profile and hypoglycaemic activity of Ajuga iva L. Food Bioscience 36: 100578. doi: 10.1016/j.fbio.2020.100578

[26] Kouri, G., Tsimogiannis, D., Bardouki, H., Oreopoulou, V. (2007): Extraction and analysis of antioxidant components from Origanum dictamnus. Innovative Food Science and Emerging Technologies 8: 155-162. doi: 10.1016/j.ifset.2006.09.003

[27] Makni, M., Haddar, A., KriaA, W., Zeghal, N. (2013): Antioxidant, free radical scavenging and antimicrobial activities of Ajuga iva leaf extracts. International Journal of Food Properties 16: 756-765. doi: 10.1080/10942912.2011.561465

[28] Merghem, R., Jay, M., Viricel, M.R., Bayet, C., Voirin, B. (1995): Five 8-benzylated flavonoids from Thymus hirtus (Labiateae). Phytochemistry 38: 637-640. doi:10.1016/0031-9422(94)00578-H

[29] Miliauskas, G., Venskutonis, P.R., Van Beek, T.A. (2004): Screening of radical scavenging activity of some medicinal and aromatic plant extract. Food Chemistry 85: 231-237. doi: 10.1016/j.foodchem.2003.05.007

[30] MolyneuX, P. (2004): The use of the stable free radical diphenylpicrylhydrazyl (DPPH) for estimating antioxidant activity. Songklanakarin Journal of Science and Technology 26: 211-219.

[31] OyAIZU, M. (1996): Studies on products of browning reactions: antioxidative activities of products of browning reaction prepared from glucosamine. Japanese Journal of Nutrition 44: 307-315. doi: 10.5264/eiyogakuzashi.44.307

[32] Ozturk, M., Aydogmus-Ozturk, F., Duru, M.E., Topçu, G. (2007): Antioxidant activity of stem and root extracts of Rhubarb (Rheum ribes): an edible medicinal plant. Food Chemistry 103: 623-630. doi: 10.1016/j.foodchem.2006.09.005 
[33] RatTy, A.K., DAS, N.P. (1988): Effect of flavonoids on nonnenzymatic lipid peroxidation: Structure-activity relationship. Biochemical medicine and Metabolic Biology 39: 69-79.

[34] RobBins, R. (2003): Phenolic acids in foods: An overview of analytic methodology. Journal of Agricultural and Food Chemistry 51: 2866-2887. doi: 10.1021/jf026182t

[35] Salucci, M., Stivala, L.A., Vannini, V. (2002). Flavonoids uptake and their effect on cell cycle of human colon adenocarcinoma cells. British Journal of Cancer 86: 16451651. doi: 10.1038/sj.bjc.6600295

[36] ShahIDI, F.P.K.J, Wanasundara, P.D. (1992): Phenolic antioxidants. Critical Reviews in Food Science and Nutrition 32 (1): 67-103. doi: 10.1080/10408399209527581

[37] Shimada, K., Fujikawa, K., Yahara, K., Nakamura, T. (1992). Antioxidative properties of xanthin on autoxidation of soybean oil in cyclodextrin emulsion. Journal of Agricultural and Food Chemistry 40: 945-948. doi: 10.1021/jf00018a005

[38] Taleb-Senouci, D. Ghomari, H., Krouf , D., Bouderbala, S., Prost, J., LacailleDubois, M.A., BouchenAK, M. (2009). Antioxidant effect of Ajuga iva aqueous extract in streptozotocin-induced diabetic rats. Phytomedicine 16: 623-631.

doi:10.1016/j.phymed.2008.12.004

[39] TripathI, Y.B., Singh, A.V. (2001). Effect of Semecarpus anacardium nuts on lipid peroxidation. Indian Journal of Experimental Biology 39: 798-801.

[40] Vamanu, E., Nita, S. (2013): Antioxidant capacity and the correlation major phenolic compounds, anthocyan, and tocopherol content in various extracts from the wild edible Boletus edulis mushroom. BioMed Research International ID: 313905. doi: $10.1155 / 2013 / 313905$

[41] Van Acker, S.A.B.E., Van Balen, G.P., Van Den Berg, D.J., Bast, A., Van Der VIJGH, W.J.F. (1998): Influence of iron chelation on the antioxidant activity of flavonoids. Biochemical Pharmacology 56: 935-943.

doi: 10.1016/S0006-2952(98)00102-6

[42] Velioglu, Y.S., Mazza, G., GaO, L., OOMAH, B.D. (1998): Antioxidant activity and total phenolics in selected fruits, vegetables and grain products. Journal of Agricultural and Food Chemistry 46: 4113-4117. doi: 10.1021/jf9801973

[43] Wojdylo, A., Oszmianski, J., CZEMERys, R. (2007): Antioxidant activity and phenolic compounds in 32 selected herbs. Food Chemistry 105: 940-949. doi: 10.1016/j.foodchem.2007.04.038

[44] Wong, S.P., LeONG, L.P., William KoH, J.H. (2006): Antioxidant activities of aqueous extracts of selected plants. Food Chemistry 99 (4): 775-783.

doi: 10.1016/j.foodchem.2005.07.058

[45] YANG, J., GuO, J., YUAN, J. (2008). In vitro antioxidant properties of rutin. Food science and technology 41 (6): 1060-1066. doi: 10.1016/j.lwt.2007.06.010

[46] ZAFAR, H.I., BADIÀA, L. (2009): Ethnopharmacology of the plants of the genus Ajuga. Pakistan journal of pharmaceutical sciences 22 (4): 425-462.

[47] Zerroug, M.M., Zouaghi, M., Boumerfeg, S., Baghiani, A., Nicklin, J., Arrar, L. 2011. Antibacterial activity of extracts of Ajuga iva and Teucrium polium. Advances in Environmental Biology. 5 (2), 491-495. 
[48] Zhang, M., Swarts, S.G., Yin, L., LiU, C., Tia, Y., CaO, Y., Swarts, M., Yang, S., Zhang, S.B., Zhang, K., Ju, S., OleK, D.J., Schwartz, L., Keng, P.C., Howemll, R., ZhANG, L., OKUNIEFF, P. (2011): Antioxidant properties of quercetin. Advances in Experimental. Medicine and Biology 701: 283-289. doi: 10.1007/978-1-4419-77564_38 